\title{
OPEN Author Correction: Collective behaviour in 480-million-year-old trilobite arthropods from Morocco
}

\section{Jean Vannier, Muriel Vidal, Robin Marchant, Khadija El Hariri, Khaoula Kouraiss, Bernard Pittet, Abderrazak El Albani, Arnaud Mazurier \& \& Emmanuel Martin}

Correction to: Scientific Reports https://doi.org/10.1038/s41598-019-51012-3, published online 17 October 2019

This Article contains errors in Figure 5: the red circles depicting chemical signals are missing in panel $\mathrm{f}$ and the labelling of panels b, c, e and f, as well as the antennule, genal and glabellar spine, are incorrect. As a result, the Figure legend,

“(a-c) Response to oriented environmental stress (e.g. storms); hydrodynamic signal (higher current velocity represented by white arrows) received by motion sensors triggers re-orientation of individuals; mechanical stimulation and/or possible chemical signals cause gathering, alignment and locomotion in group. (d-f) Seasonal reproductive behaviour; chemical signals (e.g. pheromones; see red circles and red arrows) cause attraction and gathering of sexually receptive individuals (males and females) and migration to spawning grounds. The alignment of individual may have been controlled by mechanical stimuli (as in a-c). Olfactive and mechanical sensors were probably located on the antennules (pink areas 4,5), and genal and glabellar spines (green areas 1-3), respectively. The exact location of mechanoreceptors is uncertain (possibly on high-relief exoskeletal features such as the glabella)."

should read:

“(a-c) Response to oriented environmental stress (e.g. storms); hydrodynamic signal (higher current velocity represented by white arrows) received by motion sensors triggers re-orientation of individuals; mechanical stimulation (small green circles) and/or possible chemical signals cause gathering, alignment and locomotion in group. (d-f) Seasonal reproductive behaviour; chemical signals (e.g. pheromones; see red circles and red arrows) cause attraction and gathering of sexually receptive individuals (males and females) and migration to spawning grounds. The alignment of individual may have been controlled by mechanical stimuli (as in a-c). Olfactive and mechanical sensors were probably located on the antennules (pink areas 1,2), and genal and glabellar spines (green areas 3-5), respectively. The exact location of mechanoreceptors is uncertain (possibly on high-relief exoskeletal features such as the glabella)" 
The correct Figure 5 and the correct Figure legend appear below as Figure 1.

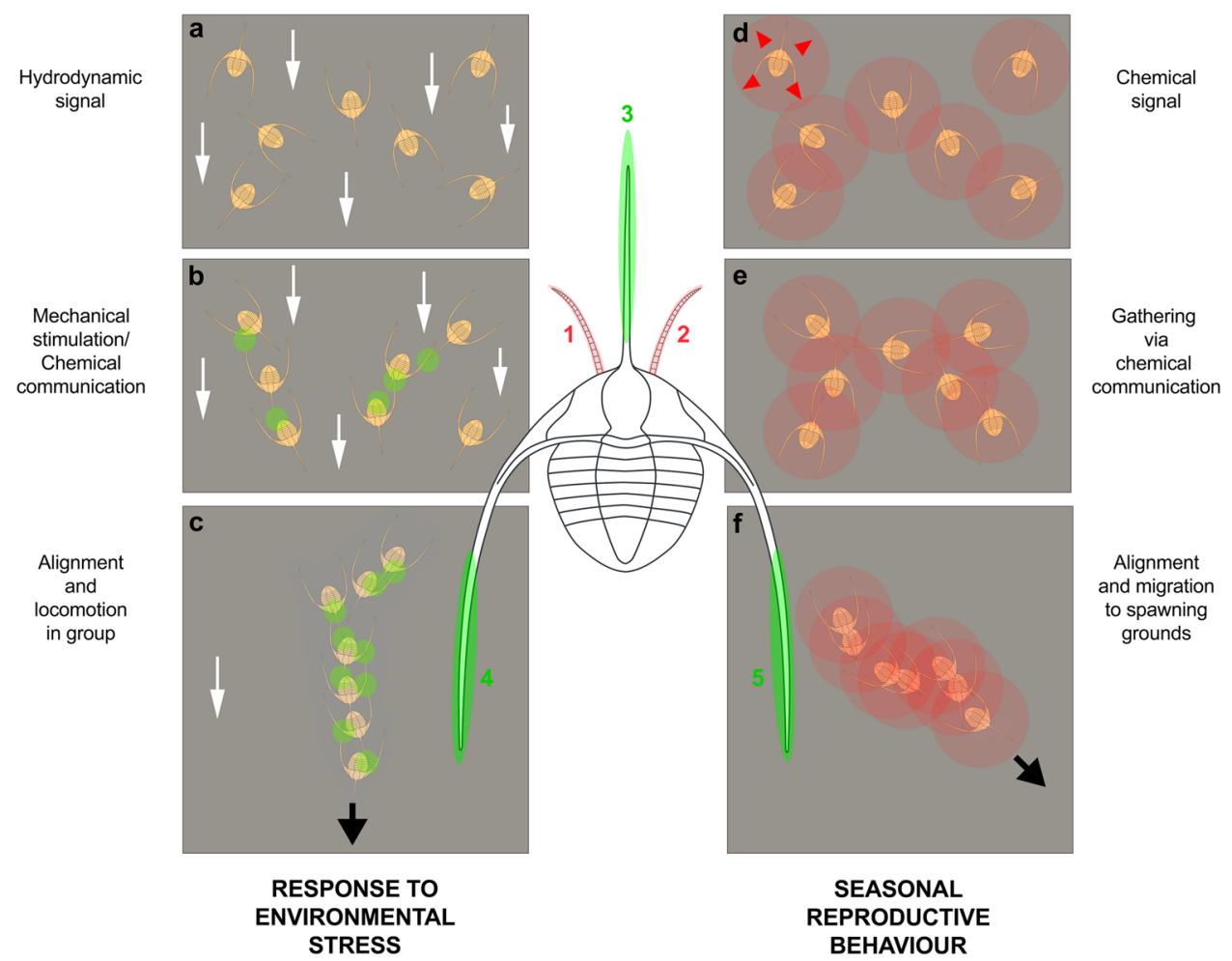

Figure 1. Two non-exclusive hypotheses to explain the linear clusters of Ampyx priscus from the Lower Ordovician of Morocco. (a-c) Response to oriented environmental stress (e.g. storms); hydrodynamic signal (higher current velocity represented by white arrows) received by motion sensors triggers re-orientation of individuals; mechanical stimulation (small green circles) and/or possible chemical signals cause gathering, alignment and locomotion in group. (d-f) Seasonal reproductive behaviour; chemical signals (e.g. pheromones; see red circles and red arrows) cause attraction and gathering of sexually receptive individuals (males and females) and migration to spawning grounds. The alignment of individual may have been controlled by mechanical stimuli (as in $\mathbf{a}-\mathbf{c})$. Olfactive and mechanical sensors were probably located on the antennules (pink areas 1,2), and genal and glabellar spines (green areas 3-5), respectively. The exact location of mechanoreceptors is uncertain (possibly on high-relief exoskeletal features such as the glabella).

(i) Open Access This article is licensed under a Creative Commons Attribution 4.0 International License, which permits use, sharing, adaptation, distribution and reproduction in any medium or format, as long as you give appropriate credit to the original author(s) and the source, provide a link to the Creative Commons license, and indicate if changes were made. The images or other third party material in this article are included in the article's Creative Commons license, unless indicated otherwise in a credit line to the material. If material is not included in the article's Creative Commons license and your intended use is not permitted by statutory regulation or exceeds the permitted use, you will need to obtain permission directly from the copyright holder. To view a copy of this license, visit http://creativecommons.org/licenses/by/4.0/.

(c) The Author(s) 2020 